Revue d'histoire de l'Amérique française

ZWB REVUE D.HISTOIRE DE L'AMÉRIQUE FRANÇAISE

\title{
Lettre de Louis-Joseph Papineau à M. J.-J. Girouard, 27 juillet 1855
}

Volume 6, numéro 4, mars 1953

URI : https://id.erudit.org/iderudit/301555ar

DOI : https://doi.org/10.7202/301555ar

Aller au sommaire du numéro

Éditeur(s)

Institut d'histoire de l'Amérique française

ISSN

0035-2357 (imprimé)

1492-1383 (numérique)

Découvrir la revue

Citer ce document

(1953). Lettre de Louis-Joseph Papineau à M. J.-J. Girouard, 27 juillet 1855.

Revue d'histoire de l'Amérique française, 6(4), 569-570.

https://doi.org/10.7202/301555ar d'utilisation que vous pouvez consulter en ligne.

https://apropos.erudit.org/fr/usagers/politique-dutilisation/ 


\section{L.-J. Papineau à Monsieur J.-J. Girouard}

\section{Mon cher Monsieur Girouard,}

Depuis que je vous ai écrit pour vous dire que mon épouse ma famille et moi désirions fort que vous nous fissiez l'amitié de nous venir voir avec nos autres amis de St Benoit, Monseigneur de Byetown a choisi le premier mardi d'août prochain pour le jour où il bénira notre petite chapelle funeraire et de famille. Il y a trente trois ans que dans cet établissement alors à son berceau, vous êtes venu avec tant de bons amis, dont si peu survivent, assister à la bénédiction de l'église paroissiale. Depuis lors la même cérémonie s'est répétée pour deux autres églises paroissiales dans la ci-devant seigneurie de la petite Nation. Aucune réunion ne peut se répéter pour nous, à nos âges, comme celles qui avaient lieu alors, quand des natures aussi heureuses, que celles de mon Père, de Messieurs Félix \& Dumouchel donnaient l'ordre, le signal \& l'exemple d'être gais. Depuis lors ils nous ont laissés \& la gaité a été ensevelie avec eux. Les années se sont accumulées \& bien plus encor les Deuils \& les chagrins. Néanmoins quand des Anciens amis comme vous \& moi se revoient, ce sont des jours de rajeunissement, puisque nous avons peu à dire des événemens contemporains \& beaucoup à dire des événemens passés; nous nous fesons illusion pendant quelques instants, en parlant du bon vieux tems, ou nous éprouvions bien des contrariétés tout comme depuis, mais où pour chaque contretems qui nous chagrinait, mille espérances nous déridaient. Venez voir vos ainés \& les consoler, Madame Dessaulles, Madame Benjamin Papineau ${ }^{13}$, Mon épouse et moi, ce sera couvre de sharité \& d'amitié dont tous, nous serons bien reconnaissans. Si vous ne veniez qu'avec des hommes, les voitures publiques suffiraient. Mais si vous ajoutez au plaisir que nous donnera votre bonne compagnie celui que nous donnerait votre bonne compagne, si elle veut bien nous faire cette amitié, où quelqu'autre Dame, la voiture publique est bien dure \& encombrée, les chevaux bien rosses, les chemins du long sault bien pierreux, et ce trajet bien fatigant. Au lieu que si vos bonnes voitures vous amenaient avec Mrs \& Des Dumouchel \& Lemaire, de manière à arriver à Grenville à Deux heures, vous seriez ici à quatre sans avoir éprouvé d'incommodité. Si vous avez l'obligeance de me prevenir du jour de votre arrivée, j'irai avec mes voitures vous prendre au débarquement chez Major. Le Mercredi nous aurons dans la chapelle bénie de la veille un service à la mémoire des Chers parents décédés.

Dans l'espérance de vous voir alors je vous prie de vous préparer à me répondre sur l'affaire suivante dont je vais vous entretenir. Vous avez

13. Belle-sœur de Louis-Joseph Papineau. 
me diten fait l'inventaire de ce bon brave héroīque Docteur Chénier 14 Sa Mère était son héritière. Elle a légué tout ce qu'elle avait à sa Belle fille femme du Capitaine Chénier, de Longuevil. Celle-ci depuis son veuvage s'est faite religieuse a Longueial; mais avant de faire ses vœux, elle a fait donation de Vingt-cinq Louis à cette Dame en vertu du legs de sa Belle Mère par la succession du Docteur Chénier, à ses deux belles sœeurs qui domeurent ici, l'une épouse de Mr Louis Thibeaudeau cultivateur peu à son aise, et l'autre épouse du père Lalonde qui sont dans une grande pauvreté. Cette somme toute modique qu'elle est, est importante pour ces deux personnes, tout à fait recommendables. Je vous demanderai donc quand j'aurai le plaisir de vous voir, si elles ont quelques chances de la recouvrer \& à qui elles devront s'adresser pour l'obtenir.

Adieu mon cher Monsieur Girouard; souhaitant que la présente vous trouve avec Madame votre épouse et votre famille ainsi que Messieurs Dumouchelle, Lemaire, leurs Dames \& leurs familles en santé \& contentement, je vous dis a tous au revoir.

Votre ami bien affectioné,

L.J. Papineau 